\title{
O ENSINO DA MATEMÁTICA NA EDUCAÇÃO INFANTIL E A LUDICIDADE NA ABORDAGEM DO PROCESSO COM CRIANÇAS DE 05 ANOS.
}

\author{
Oliveira, Fatima dos Santos \\ Faculdade de Mauá \\ santosfiaaa@yahoo.com.br \\ Silva, Zulmira Carlos de Andrade \\ Faculdade de Mauá - FAMA \\ zulmiracandrade@gmail.com \\ Soares, Maria Aparecida Ribeiro \\ Faculdade de Mauá \\ marirs008@gmail.com \\ Rafael Mariani \\ Prof $^{\mathrm{o}}$ Ms. Orientador
}

\section{RESUMO}

Educação básica retrata um período significativo no progresso integral da criança. $\mathrm{O}$ ensino da matemática nesta fase coopera de maneira coerente e efetiva para seu desenvolvimento, visto que o lúdico está inserido na infância de crianças de 05 anos de idade a abordagem do mesmo com intuito educativo possibilita a ampliação do seu desenvolvimento integral; partindo-se da hipótese de destacar a ludicidade juntamente com o contexto matemático, pois a mesma está presente na nossa vida e possui a grande relevância diária.

PALAVRAS-CHAVE: Matemática; Educação; Lúdico; Crianças.

\begin{abstract}
Basic education summary portrays a significant period in full progress. The teaching of mathematics at this stage cooperates coherently and effectively to your development, whereas the playful this inserted into the childhood of children of 05 years old the same approach to education enables expansion of your development integral; assuming the chance to highlight the playfulness together with the mathematical context, because it is present in our lives and has great relevance.
\end{abstract}

Keywords: Mathematics; Education; Ludic; Kids. 


\section{INTRODUÇÃO:}

A educação infantil, etapa da educação básica representa um período importante no desenvolvimento integral da criança. $\mathrm{O}$ ensino da Matemática nesta fase contribui de maneira coerente e efetiva para seu progresso, visto que o lúdico está inserido na infância com intuito educativo possibilita a ampliação do seu desenvolvimento integral.

Nunes (2013) considera que a função lúdica possibilita inúmeras maneiras de se manifestar; e a Matemática permeia o universo infantil em seu cotidiano. Para tanto, surge o seguinte questionamento: Qual a importância da ludicidade no desenvolvimento de habilidades da Matemática na educação infantil com crianças desta faixa etária? Sendo crianças na fase de seu desenvolvimento.

De acordo com o mesmo autor, a ludicidade como forma de aprendizagem possui uma expectativa diferente animada e divertida de aprender. A maneira de se trabalhar a Matemática na educação infantil precisa aproximar as crianças, com uma finalidade de que elas possam produzir suas próprias capacidades e assim manter a noção de que a Matemática está presente em seu dia adia.

A proposta desta pesquisa é identificar a importância da Matemática de maneira prazerosa, por meio do lúdico e situações problemas que lhe ajudarão futuramente nas resoluções de situações reais e de seu cotidiano.

Descrever a relevância da Matemática solucionando problemas e adquirindo novos conhecimentos. Propor desafios por meio de jogos e brincadeiras para que as crianças realizem diferentes modos de resoluções á partirem de situações do seu cotidiano envolvendo a Matemática. Conforme Almeida (2010) proporcionar condições de aprender de forma agradável e prazerosa.

Entretanto a relevância deste trabalho possibilita relatar a proposta lúdica juntamente com o contexto matemático. Encorajar a educação infantil a explorar com objetivos pertinentes o cotidiano da criança e o universo matemático que o cercam.

Metodologicamente, esse trabalho aderiu o tipo de pesquisa Bibliográfica a partir de materiais publicados.

De acordo Severino (2007) a pesquisa bibliográfica registro disponível, decorrente de pesquisas anteriores, em documentos impressos, como livros, artigos, teses etc. Utilizam-se dados de categorias teóricas já trabalhadas por outros 
pesquisadores e devidamente registradas. Os textos tornam-se fontes dos temas a serem pesquisados. O pesquisador trabalha a partir de contribuições dos autores dos estudos analíticos constantes dos textos.

A pesquisa contribui para desenvolvimento de estudo e análise da situação acerca de um problema. É oportuno ressaltar a Prof ${ }^{a}$. Dra. Kátia Stocco Smole (2014) autora fundamental para o embasamento; e o Referencial Curricular Nacional para Educação Infantil no qual norteou para a pesquisa proposta.

A primeira etapa da educação básica retrata um período significativo no progresso integral da criança. O ensino da Matemática nesta fase coopera de maneira coerente e efetiva para seu desenvolvimento, visto que o lúdico está inserido na infância de crianças de 05 anos de idade a abordagem do mesmo com intuito educativo possibilita a ampliação do seu desenvolvimento integral.

Essa etapa da educação básica, concedido em pré - escolas e creches que de modo qualifica como recinto institucional que institui fundação educacional privado ou públicos que zelam e educam crianças na faixa etária de cinco anos de idade no período diurno matutino e vespertino, podendo ser também em jornada integral ou parcial, concedidos e supervisionados por órgão do sistema de ensino competente, podendo-se considerar de grande relevância para seu desenvolvimento. Sendo importante ressaltar a Diretriz Curricular Nacionais da Educação Infantil (2009) "É obrigação do Estado assegurar a oferta de Educação Infantil pública de qualidade e gratuita, sem quesito de seleção".

O amplo desenvolvimento da criança é possibilitado por meio de sua primeira etapa da educação básica que a mesma proporciona, uma vez que é um indivíduo histórico que no convívio, relações e práticas dia a dia que prática, constrói sua particularidade pessoal e coletiva, interage, imagina, cria, brinca, aprende, observa, experimenta, aprende, analisa e desenvolve sentidos sobre a natureza e a sociedade, produzindo cultura.

Por intervenções das propostas pedagógicas os seguintes princípios devem ser respeitados: Éticos, Políticos e Estéticos: da sensibilidade, da criatividade, da ludicidade e da liberdade de expressão nas diferentes manifestações artísticas e culturais.

Mediante a esses princípios norteadores dispõe como objetivo garantir à criança acesso a processos de apropriação, renovação e articulação de conhecimentos e 
aprendizagens de diferentes linguagens, assim como o direito à proteção, à saúde, à liberdade, à confiança, ao respeito, à dignidade, à brincadeira, à convivência e à interação com outras crianças.

De acordo com referencial curricular nacional da educação infantil (RCNEI, 1998) A apropriação das crianças, está imersas em um universo do qual a Matemática faz parte. As crianças começam a desenvolver uma série de situações nas relações entre quantidades, espaço e números. Utilizando-se próprios recursos para que possam resolver problemas elas mergulham em um novo universo onde um simples fato de conferir figuras ou anotar a pontuação de jogos, mostrarem os dedos quando se pergunta a idade implica que em tudo está inserida a Matemática e agora ela está organizando e descobrindo novos caminhos, como começam a descobrir o mundo a seu redor nessa fase observam também o espaço e a distância quando começa a traçar caminhos está organizando seus deslocamentos e estabelecendo as referências necessárias e começa então a comparar, expor idéias, escutar o outro na formulação de regras, desta maneira a Matemática começa a serem elaboradas, e vivenciadas, as crianças agora podem então agir tomar suas decisões e produzir seus conhecimentos, poderão tomar decisões, agindo como produtoras de conhecimento e não apenas executoras de instruções.

\section{LECIONAR MATEMÁTICA NA EDUCAÇÃO INFANTIL}

Para tanto, trabalhar com a Matemática faz com que seja formado cidadãos autônomos a pensar, e que possa resolver problemas. Desta forma processo de aprendizagem vai sendo construído de acordo com a adaptação da criança ao meio em que está inserida, desta maneira quando aprende algo, significa que conseguiu ter mudanças de comportamento no meio ao qual vive e essas mudanças em geral ocorrem a partir de aprendizagem, de acordo com Piaget (1998). Neste momento a teoria de Piaget, contribui de forma a provar o conhecimento lógico-matemático que está interligado com as ações da criança que começa a explorar o mundo e seu contexto, por isso, ela começa a compreender os conceitos básicos principalmente dos números, pois tudo ao seu redor lembra a Matemática.

A Matemática é uma disciplina que envolve raciocínio tanto lógico como abstrato, nessa etapa para Smole (2014) é necessário ser feito um bom trabalho, pois 
“trabalhar com a Matemática na educação infantil deve mostrar uma proposta de indagação porque existe uma variedade de idéias matemáticas sobre números, medidas, geometrias e noções estatísticas, a uma maneira que a criança produza e conservem o prazer e a curiosidade em torno da matemática. Está proposta incorpora contextos da realidade e experiências da linguagem natural da criança no seu desenvolvendo assim as noções matemáticas, cada vez mais presentes, saber, tentar compreender como ele pensa e fazer as interferências no sentindo de levar cada aluno a ampliar progressivamente suas noções matemáticas".

\section{DESENVOLVENDO A LUDICIDADE NA MATEMÁTICA}

Existem diversas formas de manifestar a ludicidade, por meio dos jogos e das brincadeiras, das canções, das danças, entre outras atividades lúdicas; sendo uma ferramenta didático-pedagógica muito importante para o desenvolvimento, longe de ser uma concepção ingênua de passa tempo, diversão superficial.

É uma ação no qual as crianças direcionadas adquirem conhecimento, a proposta lúdica é um processo desafiador, pois não é apenas prepará-lo e aplicá-lo deve-se também participar no seu decorrer e ao mesmo tempo está observando a criança no seu desenvolvimento. Brincar é uma oportunidade para perceber distância, desenvolver noções de velocidade, tempo, força entre outros conceitos matemáticos. A importância das experiências na primeira infância e a relação da ludicidade com a matemática torna o interesse e o aprendizado da criança mais prazeroso.

A relevância deste estudo possibilita relatar a proposta lúdica juntamente com o contexto matemático, desta maneira as preocupações com o ensino da Matemática na educação infantil têm ganhado cada vez mais espaço para Smole (2014), enquanto a criança brinca aprende, de forma prazerosa e percebe a importância da Matemática por meio das possibilidades que encontra se diverte e aprende simultaneamente. Sendo assim encorajar a educação infantil a explorar com objetivos pertinentes o cotidiano da criança e o universo matemático que o cercam, de acordo com Smole (2014), a criança quando brinca está diretamente aumentando a sua capacidade cognitiva, motora, a percepção de tempo e espaço, desta forma ressaltamos a importância da utilização do lúdico nas aulas de Matemática na educação infantil. 
A proposta desta pesquisa é identificar a importância da Matemática de maneira prazerosa, por meio do lúdico e situações problemas que lhe ajudarão futuramente nas resoluções de situações reais e de seu cotidiano.

Descrever a relevância da Matemática solucionando problemas e adquirindo novos conhecimentos. Propor desafios por meio de jogos e brincadeiras para que a criança realize diferentes modos de resoluções á partir de situações do seu cotidiano envolvendo a matemática. Conforme Almeida (2010) proporcionar condições de aprender de forma agradável e prazerosa.

Analisar as brincadeiras com objetivo para qual está sendo realizada, devendo ser desafiadoras e interessantes para sua faixa etária. Permitindo assim a participação de todos no processo, e alcançando o objetivo proposto.

Para Smole, encontram-se diversas categorias diferenciadas para o trabalho de Matemática por meio de jogos e brincadeiras, podendo-se utilizar recursos predominantes em cada etapa.

Dada a importância da utilização da ludicidade por intermédio de jogos como, por exemplo, a cama de gato, amarelinha que possibilita a criança ampliar a sua sequência numérica, pois na fase dos 05 anos, a criança precisa ter contato com os números que seja em sequência ou não, mas é necessário "Nesta faixa etária aprofundam-se os conteúdos indicados para as crianças, dando-se crescente atenção à construção de conceitos e procedimentos especificamente matemáticos. Os conteúdos estão organizados em três blocos: "Sistema de numeração e Números", "Grandezas e medidas" e "Espaço e forma". (RCNEI, 1994).

Qual a importância da ludicidade no desenvolvimento de habilidades Matemática na educação infantil com crianças de 05 anos de idade?

As crianças já sabem que existem os números porque tudo em sua volta as remete a Matemática, mas ainda não associam a escola nem tem o conhecimento do que é Matemática "As medidas estão presentes em grande parte das atividades cotidianas e as crianças, desde muito cedo, têm contato com certos aspectos das medidas. $\mathrm{O}$ fato de que as coisas têm tamanhos, pesos, volumes, temperaturas diferentes” (RCNEI, 1994).

Assim podemos trabalhar a ludicidade e a imaginação utilizando-se, por exemplo, a receita de um pão, pode ser feito em feito sala, nesse momento a professora pode trabalhar capacidade, volume, medidas entre outros, quanto cabe em cada xícara, 
ou em cada colher isso leva a criança a entender as grandezas volumes capacidades numéricas e que de acordo com o objeto a quantidade vai mudando esses objetos fazem parte do seu dia -a- dia que torna mais fácil para compreensão, permitindo a criança a pensar de acordo com a pergunta da professora, ela vai criando problemas.

Para Smole (2014), “a resolução de problemas é a atividade mais legitima da Matemática, pois toda Matemática tem uma organização pautada em resoluções de problemas, modelo e crio situações e as investigações trazem novos conhecimentos." A ludicidade está presente nessas resoluções por intermédios brincadeiras e jogos que permeiam o universo infantil. Ainda nesse contexto Piaget (1998), também traz uma contribuição que diz que para produzir conhecimento tem que haver um processo de desequilibrarão, ou seja, quando nos deparamos com algo que não temos a resposta o nosso encéfalo começa a se mobilizar em busca das respostas da questão assim como relata o RCNEI (1994) ao se trabalhar com conhecimentos matemáticos, como com o sistema de numeração, medidas, espaço e formas etc., intermédio da resolução de problemas, as crianças estarão conseqüentemente, desenvolvendo sua capacidade de generalizar, analisar, sintetizar, inferir, formular hipótese, deduzir, refletir e argumentar.

A importância da ludicidade nesse processo é que enquanto as crianças se divertem ao mesmo tempo elas aprendem e colocando as também em contato com elementos que fazem a representação do simbólico fazendo que seja mais prazeroso esse momento de ensino aprendizagem, pois a ludicidade também desenvolve o conhecimento de forma prazerosa que traz significado a coisas até então desconhecidas pelas crianças. Brincando ela descobre algo novo e também tem a oportunidade de experimentar algo adquirindo novas habilidades e despertar sua curiosidade.

\section{O BRINCAR E O DESENVOLVIMENTO COGNITIVO DA CRIANÇA}

Para Piaget, (1998) o desenvolvimento cognitivo de uma criança é algo gradual, aonde ela vai se capacitando em níveis cada vez mais complexos do seu conhecimento sempre seguindo uma sequência lógica, os estágios são definidos de acordo com que a criança vai interagindo com a realidade, visando sempre à adaptação e assim modificações progressivas dos sistemas de acomodação e assimilação.

Para ele, a etapa pré-operacional que compreende a criança de 05 anos, onde ela começa a construir sistemas de ação, ou seja, sistemas representativos onde substitui 
pessoas ou objetos por símbolos daí a importância do lúdico para ela aprender por meio da percepção imediata.

$\mathrm{O}$ autor relata que para poder produzir conhecimento deve haver um processo de desequilíbrio e acomodação do conhecimento, quando o cérebro se depara com algo que não tenha resposta ela procura se mobilizar para encontrar a resposta na qual ele se deparou, isso seria a resolução de problemas.

Para Smole (1996), a resolução de problemas é a atividade mais legitimas da matemática, que está relacionada à solução de problemas se tenho um problema preciso resolver modelando situações e traçando novas teorias matemáticas, na vida nos deparamos com várias problemáticas por isso a criança precisa ter esse contato logo ainda cedo, para se preparar para o futuro, tudo envolve a resolução de problemas e o uso da Matemática, fazendo a criança vivenciar uma variedade de situações problemas que farão despertar a curiosidade e o interesse, quando ela vivencia resoluções ela começa a desenvolver o seu raciocínio lógico, para tanto se utilizar do lúdico como ferramenta para desenvolver esse trabalho trazendo a criança para o mundo a matemática de uma forma prazerosa.

Ainda para a autora o que as crianças precisam ao final da educação infantil é identificar os números escritos e falados, podendo aprender em toda parte não somente na escola, mas em todo seu cotidiano em casa, por exemplo, quando identificam o canal que deseja assistir já está conseguindo identificar um número, porém não sabem que estão inseridas no mundo da Matemática e que isso tem relação com a escola, porém já é um contato com o mundo matemático, isso demonstra que antes de irem para a escola as crianças já vivenciam um contato com a Matemática.

Pode-se dizer que o jogo auxilia mediando na invenção e exploração, diminuindo a conseqüência os desacertos e insucesso da criança, possibilitando desenvolver sua decisão, sua objetividade, sua autonomia. Contudo, o jogo é uma atividade séria que não tem resultados decepcionante para a criança. (SMOLE, 1996, p. 138)

Sendo assim para o aprendizado da Matemática, e o uso da ludicidade deve ter uma finalidade, de aumentar capacidades importante tais como, a percepção, atenção, a memorização, a criatividade, a ideia de espaço e tempo.

Por esses aspectos é que podemos alegar que o jogo possibilita cenários que, podem ser semelhante a problemas, requerem respostas significativas, originais, 
veloz. Nesse caso, a preparação, a demanda mais adequada e a finalidade de conhecimentos obtidos anteriormente permitem o alcance de novas idéias, novas percepção [...] (SMOLE, 1996, p. 138)

Para Kishimoto (2000), o jogo serve como meio de estimular a exploração e encontrar soluções para problemas propostos e, precisa ser prazeroso e espontâneo para que a criança sinta-se livre de pressões cognitivas.

Neste ponto de vista, o jogo torna-se conteúdo importante, com o intuito de realizar capacidades de desenvolturas de problemas, permitindo ao aluno o ensejo de determinar projetos de ação para conquistar estipulados objetivos [...] (KISHIMOTO, 2000, pp. 80 - 81)

Neste contexto conforme as autoras jogos trazem problemas, à criança precisa encontrar uma maneira de solucionar o problema assim, a criança desenvolve estratégias e aprende de forma que surgem os problemas o lúdico ajuda a encontrar a solução.

Metodologicamente esse trabalho aderiu o tipo de pesquisa Bibliográfica a partir de materiais publicados. A finalidade é colocar o pesquisador em contato direto com tudo aquilo que foi escrito sobre determinado assunto, ou seja, possibilitaram ampliar o conhecimento por meio de autores no qual desenvolveu artigos, livros, revistas entre outras matérias publicadas. Desse modo, adotar a pesquisa bibliográfica proporcionou trabalhar de maneira que o tema que norteia esse trabalho seja interpretado e compreendido de forma realista em torno do que foi proposto, fundamentada em teóricos, na intenção de construir interesse na busca de mais informações, para Gil (2010), obter este tipo de estudo visa proporcionar um maior conhecimento para o pesquisador acerca do assunto, a fim de que esse possa formular problemas mais precisos ou criar hipóteses que possam ser pesquisadas por estudos posteriores.

Dessa maneira a pesquisa qualitativa e voltada para a preocupação com questões voltadas para esclarecimentos de assunto pertinente as ciências sociais, ainda para Gil (2010), a pesquisa bibliográfica possibilita um amplo alcance de informações, alem de permitir a utilização de dados dispersos em inúmeras publicações, auxiliando também na construção, ou na melhor definição do quadro conceitual que envolve o objeto de estudo proposto. 


\section{CONSIDERAÇÕES FINAIS}

De acordo com os autores que embasaram este trabalho, a Matemática está inserida em todo cotidiano da criança. Na idade de cinco anos a idade em questão do nosso trabalho, deve-se ensinar Matemática considerando aspectos do conhecimento de números, medidas e espaço, com está informação utiliza-se o lúdico como ferramenta.

As atividades matemáticas não devem iniciar-se apenas no ensino fundamental, pois não se baseia diversas situações que devem ser memorizados, portanto compreender o ensino da Matemática na Educação Infantil deve trazer uma reflexão sobre as práticas educativas e a sua importância nesta fase de iniciação para a escolarização. Neste contexto o professor é de total importância para a criança nessa etapa por propiciar um ambiente exploratório que demonstre que a Matemática não é apenas números, mas, também medidas, tempo e espaço, cabe a ele utilizar-se do lúdico de forma prazerosa para que as crianças possam compreender como algo que está inserida em suas vidas e sua total importância. A ludicidade precisa ser aplicada com objetivos, que alcance sucesso. A interação, a socialização utilizada do lúdico desperta o interesse para compreender melhor o ensino matemático e troca de informações são indispensáveis nas aulas onde as crianças aprendem brincando e se divertindo, uma maior interação entre os alunos e professores sanando a lacuna existente entre ensino da Matemática na educação infantil e o ensino fundamental tornado assim as etapas conseqüente tão prazerosa como as das etapas anteriores. Jogos e brincadeiras trazem um suporte, na abordagem desse processo, lembrando que nessa fase de crianças de cinco anos, a criança está em uma transição para o ensino fundamental, por essa razão é primordial que a Matemática seja bem trabalhada, com resoluções de problemas se utilizado do lúdico enquanto se divertem aprendem, resolvendo as situações propostas com facilidade elevam seu conhecimento matemático.

Sabendo-se que jogos envolvem regras, e brincar é algo espontâneo que são importantes para aspectos de desenvolvimento da criança é uma facilidade no ensino aprendizagem dada à importância da abordagem onde o lúdico é a ferramenta indispensável na etapa em questão.

Concluímos a relevância da ludicidade juntamente com o contexto matemático, permitindo assim aprender a Matemática de forma descomplicada e prazerosa, transformando o momento de construção de conhecimento agradável e aplicável ao cotidiano da criança. 


\section{REFERÊNCIAS}

ALMEIDA, Paulo Nunes de. Educação lúdica: técnicas e jogos pedagógicos. São Paulo, SP: Loyola, 2010.

BRASIL. Secretaria de Educação Fundamental. Referenciais Curriculares Nacionais de Educação Infantil. Vol. 3. Brasília: 1998. Disponível em < http://portal.mec.gov.br/ >.

GIL, Antonio Carlos. Como Elaborar Projetos de Pesquisa. 5a ed. São Paulo: Atlas, 2010 .

KISHIMOTO, Tizuco Morchida. Jogo, brinquedo, brincadeiras e a educação. $4^{a}$ Ed. São Paulo, Editora Cortez: 2000.

NUNES, Ana R. S. C. A. O Lúdico na Aquisição da Segunda Língua. Disponível em //www.linguaestrangeira.pro.br/artigos_papers/ludico_linguas.htm.

SEVERINO, Antonio Joaquim. Metodologia do Trabalho Científico. 23. ed. ver. e ampl. de acordo com a ABNT. São Paulo: Cortez, 2007.

PIAGET, J. A psicologia da criança. Ed. Rio de Janeiro: Bertrand Brasil, 1998.

SMOLE, Kátia Stocco. A matemática na educação infantil: a teoria das inteligências múltiplas na prática escolar. Porto Alegre. Artes Médicas, 1996.

SMOLE, Kátia Stocco. Brincadeiras infantis na aula de matemática. Porto Alegre. Artes Médicas, 2014. 